\title{
Red-listing saproxylic beetles in Fennoscandia: current status and future perspectives
}

\author{
Atte Komonen*, Mats Jonsell, Thomas Ranius \\ Department of Ecology, Swedish University of Agricultural Sciences, Box 7044, 75007, Uppsala, Sweden
}

\begin{abstract}
This paper reviews the use of the International Union for the Conservation of Nature and Natural Resources, World Conservation Union (IUCN) Red List criteria for saproxylic beetles (Coleoptera) in Sweden and Finland. Of the red-listed saproxylic beetle species, $86 \%$ have been redlisted, based on Criterion B, and $12 \%$ based on Criterion D, both of which are related to range size. Criteria A (population reduction) and E (quantitative analysis) have not been applied at all, and C (small population size) in few cases only. We argue that there are great challenges in applying objectively the IUCN Red List criteria to saproxylic beetles in national assessments. To meet these challenges, there is a need for well-designed surveys to obtain better estimates of range size, monitoring schemes to detect temporal trends and population level studies to fully evaluate the extinction risk of isolated populations.
\end{abstract}

KEY WORDS: Coleoptera $\cdot$ Extinction risk $\cdot$ IUCN $\cdot$ Population size estimate $\cdot$ Population viability analysis $\cdot$ Range size

Resale or republication not permitted without written consent of the publisher

\section{SETTING THE SCENE}

A saproxylic species is an organism 'that is dependent, during some part of its life cycle, upon the dead or dying wood of moribund or dead trees, or upon wood-inhabiting fungi, or upon the presence of other saproxylics' (Speight 1989). These species comprise 20 to $25 \%$ of all forest species in Finland (Siitonen 2001), and many of them are under threat, because they severely compete for woody substrates with humans. The largest numbers of saproxylic invertebrate species are found in Coleoptera (beetles), Diptera (flies) and Hymenoptera (wasps), and these groups have also the largest number of red-listed species (Rassi et al. 2001, Gärdenfors 2005). Despite the advanced level of taxonomic knowledge in Fennoscandia, Coleoptera was the only one of these taxa which was evaluated in full during the Red List assessment, and is therefore the focal group of the present study.

Due to their concealed life-style, saproxylic beetles are generally difficult to sample and study, and thus present a challenge for Red List assessment and con- servation research. As Sweden and Finland are among the nations that have applied the International Union for the Conservation of Nature and Natural Resources, World Conservation Union (IUCN) Red List criteria (IUCN 2001) and regional guidelines (IUCN 2003), we present views on the suitability of the IUCN criteria for national assessment of saproxylic beetles and pinpoint some future challenges for research that aims at improving the data useful in national Red List assessments. The notations for the subcriteria used in this paper follow IUCN (2001). These were used in the Swedish 2005 Red List (Gärdenfors 2005), but not in the Finnish 2000 Red List (Rassi et al. 2001).

\section{CRITERION A: POPULATION REDUCTION}

Criterion A deals with population reduction (e.g. $>30 \%$ in $10 \mathrm{yr}$ ). Such reduction does not have to be observed: it may also be estimated, inferred or suspected based on a decline in habitat quality, for example. This criterion has not been used for any saproxylic 
beetle species. The main reason for this is the lack of detailed knowledge on the population or range size now, and in the past, which would allow quantitative analysis of population reduction. For Lepidoptera (butterflies and moths) and Aves (birds), for example, there are better time series available, and thus the A criterion has been applied more often (Table 1).

Our view is that the time window of 10 yr (or 3 generations) for population decline is too short for saproxylic beetles. To document a population reduction in a 10 yr period requires very good field data; yet the possible trend would be difficult to distinguish from background noise. The time window for assessing population decline should also be related to the turnover time of the substrate. Advanced decay stages and hollow trees have long turnover rates and in many cases 10 s of beetle generations can reproduce in the same tree. Thus, a detectable response of beetle populations to changes in forest landscapes is unlikely in short time periods. There are empirical and modeling studies which show that there might be considerable time lags in the response of saproxylic species to habitat loss and fragmentation (Komonen et al. 2000, Ranius \& Kindvall 2006). Criterion A can thus only be used for species with very clear short-term trends, not for species with continuous, gradual decrease, as might be the case for many saproxylic beetles in Fennoscandia.

Criterion A is important, however, as it is the main criterion that can be used for widespread but declining species. The other criteria assume either a small range or small population size. There are probably many widespread saproxylic beetle species that are not classified as red-listed, although they should be because either their range or population size is declining. Wellknown forest-dwelling birds (e.g. the willow tit in Sweden) and mammals (e.g. the Siberian flying squirrel in Finland) are good examples of such species, and since saproxylic beetles are influenced by the same forest management regime it is not unlikely that they are also experiencing large-scale gradual declines.

Table 1. IUCN Red List criteria used in the national assessment of saproxylic beetles in Sweden and Finland, and for Lepidoptera and Aves in Sweden showing the no. of species assessed as meeting each criterion. Note that the criteria have been applied only for Critically Endangered, Endangered and Vulnerable, and $>1$ criterion per species has been used if appropriate. Spp.: total no. of species

\begin{tabular}{|lcccccc|}
\hline & \multicolumn{7}{c|}{ Criteria } \\
\cline { 2 - 7 } & A & B & C & D & E & Spp. \\
\hline Sweden & & & & & & \\
$\quad$ Saproxylic Coleoptera & 0 & 168 & 7 & 4 & 0 & 172 \\
$\quad$ Lepidoptera & 13 & 230 & 7 & 32 & 0 & 179 \\
$\quad$ Aves & 18 & 2 & 23 & 36 & 0 & 43 \\
Finland & & & & & & \\
$\quad$ Saproxylic Coleoptera & 0 & 116 & 0 & 37 & 0 & 130 \\
\hline
\end{tabular}

\section{CRITERION B: GEOGRAPHIC RANGE}

Criterion B has been used to classify $86 \%$ of the redlisted saproxylic beetle species in Sweden and Finland. The criterion requires that in addition to a limit to the geographic range, at least 2 of the following subcriteria are met: (a) the distribution is severely fragmented or the species exists in $<10$ locations, (b) the geographic range is decreasing, or (c) the populations are strongly fluctuating. There are no numerical thresholds for (b) and (c) (cf. criterion A) in the IUCN guidelines, although in Finland the time window for range reduction has been set at $10 \mathrm{yr}$ and and to be classified as 'strongly fluctuating', populations must fluctuate by at least one order of magnitude.

Data behind Criterion B are mainly based on records from insect collections and surveys initiated by nature conservation authorities. Based on expert opinion, these limited data are then extrapolated to yield estimates of area of occupancy. As the observed area of occupancy may be an underestimate of the true range size up to several orders of magnitude (Martikainen 2002), extrapolation is necessary. However, a problem is that currently the estimates cannot be evaluated, as neither the explicit quantitative analyses behind the extrapolations nor the actual estimated area of occupancy have been published.

Criterion B is the main criterion applicable to invertebrates, but are the available data sufficient to be able to objectively apply this criterion to saproxylic beetles? Subcriterion (a) is the most straightforward to use, although the concept of fragmentation is related to species' dispersal ability, which is poorly known for almost all saproxylic beetles. The application of subcriteria (b) and (c) is challenging even with good data. Where (b) has been used, the continuing decline is mostly inferred based on the decline in habitat area or quality (e.g. area of old-growth forests; Rassi et al. 2001). As there is no information available on fluctuations, subcriteria (c) cannot typically be used. So, the application of Criterion B is largely dependent on how much one is willing to infer about range or habitat decline and fluctuations, and what time window is used.

\section{CRITERION C: SMALL POPULATION SIZE AND CONTINUING DECLINE}

Species may be red-listed according to Criterion $\mathrm{C}$ if the number of individuals is small $(<10000)$ and the population size is continuously declining. In Sweden, only 1 saproxylic beetle spe- 
cies has been red-listed according solely to Criterion $\mathrm{C}$, whereas for the other 6 species both Criterion $\mathrm{C}$ and Criterion B were used. The reason why this criterion is seldom used is that population sizes have rarely been estimated, and from those studies that exist, it seems that hundreds of individuals of even the rarest saproxylic beetle species may occur in a single dead tree; however, a viable local population must typically have many trees (Siitonen \& Saaristo 2000, Ranius 2001). So for the majority of saproxylic beetles the population size is probably more than the critical threshold of 10000 ind. We suggest that rather than using the number of individuals as a measure of local population size, the number of occupied trees would be a better index of population size, as is the case with mosses and lichens (Gärdenfors 2005). Nevertheless, there is an urgent need to gather more information about population sizes and dynamics to quantify the extinction risk of small, isolated populations. Such information is also needed for other criteria (A, B1b,C, B2b,C, E) and would complement assessments performed using the range-based criteria.

\section{CRITERION D: VERY SMALL OR RESTRICTED POPULATION}

Criterion D assumes only a small number of individuals (D1) or range size (D2), and not fluctuation or decline in these parameters. According to the IUCN (2001) guidelines, only D1 has quantitative thresholds for each threat category. In Finland, however, quantitative thresholds have also been applied for D2, which may explain why it has been used more than in Sweden. It is the only criterion for 14 species in Finland and 3 species in Sweden, but it has mostly been applied in combination with Criterion B.

In general, D2 is a particularly suitable criterion for species that are naturally rare, for instance due to a limited distribution of their host tree. Such species constitute $43 \%$ of the red-listed longhorn beetles in Finland (Komonen 2007). Yet, these peripheral species, i.e. species that are at the edge of their global geographical range, have mostly been classified using Criterion $B$, because the threshold for classification as 'Vulnerable' under D2 is too rigid $\left(<100 \mathrm{~km}^{2}\right.$ according to the previous IUCN guidelines and $<20 \mathrm{~km}^{2}$ according to the 2001 guidelines). As peripheral species have rarely declined considerably in range size, and there are no data available on population fluctuations, Criteria B1b,c and B2b,c are often not applicable. So, are these species not threatened? This might be the case, but this seems counterintuitive, and thus the species are 'forced' onto the redlist under the B criterion-forced in the sense that there might be few data to back up such assessments.

\section{CRITERIA E: QUANTITATIVE ANALYSIS}

Quantitative analysis in the form of Population Viability Analysis (PVA) has not been formally used for any saproxylic invertebrate species in Red List assessment. As a minimum, PVA requires good population size data over many years and preferably also demographic data. We are only aware of a PVA for 1 saproxylic beetle, Osmoderma eremita, in the scientific literature (Ranius 2007). Even though longer time series on population sizes were available for this species than for any other threatened saproxylic beetle, the uncertainties in the extinction risk assessment were still large. However, the reliability of the outcome was improved by validation using field data on current occurrence patterns (Ranius 2007). Although it seems to be very difficult to do a demographic PVA for the majority of saproxylic species, there are count-based PVA methods which could be used if the population size can be determined accurately enough and monitored for many years (Morris \& Doak 2002).

\section{FUTURE DIRECTIONS}

\section{Need for better documentation}

Range size is the the most practical measure to assess extinction risk of saproxylic beetles, but it is necessary to obtain formal, quantitative estimates of range size. The current practice of using extrapolations based on expert opinions, which are not reported and are thus not subjected to scientific scrutiny, is an unsatisfactory practice. If the logic behind the extrapolations is not documented in detail, then such estimates cannot be verified in the field.

\section{Better estimates of range size}

Reliable estimates of range size require knowledge on species habitat requirements. If habitat requirements are known, estimation can be based on vegetational maps, forestry data (Siitonen \& Saaristo 2000) or habitat suitability models (Buse et al. 2007). If habitat requirements are not understood in detail, there is a risk that estimates become unreliable and species will be sampled at the wrong places in field surveys.

A strongly held view prior to the late 1990s was that most red-listed saproxylic beetles in boreal forests need late successional, closed-canopy forests with characteristic microclimatic conditions (i.e. old-growth; Rassi et al. 2001). Thus, searching effort was directed mostly to such habitats, and this has certainly affected the expert estimates of range size. Today we know that 
this view is not the whole truth: for example, $91 \%$ of the red-listed saproxylic beetles in Finland and $59 \%$ in Sweden are indifferent in terms microclimate or even prefer sun-exposed conditions (Jonsell et al. 1998, Tikkanen et al. 2006). These species are not strictly confined to old-growth forests and can occur in many locations where there are suitable substrates and potential source populations in the surrounding landscape. It is clear that the above-mentioned paradigm shift has implications on range size estimation but, at the same time, makes reliable estimation more difficult, as species range size cannot be simply deduced from the area of old-growth forests.

\section{Population level studies}

Range size is not sufficient to assess a species' extinction risk, and without data on population size and fluctuations, the options that can be used to redlist saproxylic beetles are limited. There have recently been attempts to assess the occurrence and population size of saproxylic beetles. The methods have included counting larvae (Siitonen \& Saaristo 2000), which is often applicable for phloem-feeding species. As there is often high mortality among larvae (Martikainen 2002), larval censuses may overestimate effective population size during reproduction. For some wood-living species, documenting the characteristic emergence holes is a suitable method to evaluate population size (Wikars 2004, Buse et al. 2007).

Mark-recapture techniques are useful to estimate local population sizes and, if conducted over years, they provide information on population fluctuations. Mark-recapture techniques have been used to estimate local population sizes of 2 flower-visiting longhorn beetle species (Tikkamäki \& Komonen 2006) and a species living in hollow oaks (Ranius 2001). For most saproxylic beetles, however, population estimations based on this technique would probably become uncertain, due to small recapture probability because the adults are too difficult to find. But, as illustrated above, there are many field methods available to estimate range and population size and these can be, and should be, carried out systematically.

\section{Research should challenge Red Lists}

Given the often limited data behind red-listing, the reliability of Red List assessment has to be evaluated. At the moment, there are few studies that have focused on red-listed saproxylic beetles (Table 2). Such research has provided important information about species habitat requirements and distribution, which on occasions have led to downgrading species Red List status (Jonsell \& Nordlander 2002, Martikainen 2002). In order to make research directly applicable to Red List assessment, it should explicitly focus on the criteria according to which the species has been red-listed, or potentially should be red-listed, and on the thresholds that constitute the different Red List categories.

T. Tikkamäki \& A. Komonen (unpubl. data) evaluated the Red List status of Leptura maculata in Finland. The species is classified as Vulnerable according to Criterion D2: area of occupancy $<100 \mathrm{~km}^{2}$ and number of locations $(5 \times 5 \mathrm{~km}$ grid cells $)$ between 3 and 5 . The study showed that the species occurs at 12 locations, covering a total of $300 \mathrm{~km}^{2}$. This means that the species does not meet the threshold for Vulnerable under the D2 criterion. Furthermore, the mark-recapture study that was conducted in a very limited area (in 3 areas totaling $2.6 \mathrm{~km}$ stretch of roadside, and only in 1 site over the entire flight period) resulted 580 marked individuals. The D1 critical threshold for VU is 1000 ind., so given that the species occurs over an area of $300 \mathrm{~km}^{2}$, it clearly should not be classified as VU under D1 criterion. Although it is unlikely that all red-listed species can be studied in detail, this should not be used as an excuse not to conduct such studies.

The research on red-listed species should be of high priority; however, research on other species may also have important implications on red-listing. The current difficulties associated with placing saproxylic beetle

Table 2. Fennoscandian studies published in international peer-reviewed journals that have focused on habitat requirements, distribution or abundance of a particular threatened saproxylic beetle species. MRR: mark-release-recapture

\begin{tabular}{|lllll|}
\hline Species & Family & Country & Main methods & Source \\
\hline Osmoderma eremita & Scarabaeidae & Sweden & MRR of adults & Ranius (2002) \\
Tragosoma depsarium & Cerambycidae & Sweden & Emergence hole counts & Wikars (2004) \\
Acanthocinus griseus & Cerambycidae & Finland & Larval and pupal counts & Martikainen (2002) \\
$\begin{array}{l}\text { Oplocephala } \\
\text { haemorrhoidalis }\end{array}$ & Tenebrionidae & Sweden & Rearing from substrate & Jonsson et al. (2001) \\
Pytho kolwensis & Pythidae & Finland & Larval counts & Siitonen \& Saaristo (2000) \\
\hline
\end{tabular}


species on the Red List are also associated with decisions that result in species not being on the Red List. This situation greatly reduces the importance of Red List status for informing and stimulating conservation research on particular species. Comparisons of ecological traits in threatened and non-threatened sister species or larger assemblages may provide new insights in extinction risks of species currently classified as 'Near Threatened' or 'Least Concern' (Kotiaho et al. 2005), but such comparisons have rarely been made for saproxylic beetle species (but see Jonsson et al. 2001, Jonsson 2003).

\section{CONCLUSIONS}

IUCN Red List criteria offer 5 tools (A-E) to assess species extinction risk. At the moment, however, only a few of these tools are inherently appropriate for saproxylic beetles, and those which are appropriate are rarely used, due to lack of data. It is apparent that wood-dwelling bryophytes, lichens and fungi share similar problems in Red List assessment according to IUCN criteria. The fact that not all the available tools are used adequately indicates the direction in which research on red-listed species should be heading. Well-designed surveys need to be incorporated to obtain better estimates of range size, to establish monitoring schemes, to detect temporal trends and to promote population level studies with which to fully evaluate the extinction risk of isolated populations. In this endeavor, more interaction is needed between scientists and practical Red List assessment.

The general aim of the IUCN system is to provide 'an explicit, objective framework for the classification of the broadest range of species according to their extinction risk' (IUCN 2001). The specific aims include promoting consistency and comparability in Red List assessment between people, countries and taxa. To achieve these aims, the IUCN protocol provides fixed, numerical thresholds for red-listing a broad range of taxa both regionally and globally. At present, however, we do not know how well these thresholds correspond to extinction risks of species in a variety of taxonomic groups and ecosystems. As invertebrates make up most of the biodiversity on earth, the thresholds that seem to be more suitable for vertebrates may not be efficient in assessing the extinction risk of the major component of global biodiversity. Are we sacrificing the assessment of true extinction risks to consistency and comparability?

\section{LITERATURE CITED}

Buse J, Schröder B, Assmann T (2007) Modelling habitat and spatial distribution of an endangered longhorn beetle-a case study for saproxylic insect conservation. Biol Conserv 137:372-381

Gärdenfors U (ed) (2005) The 2005 Red List of Swedish species. ArtDatabanken, Uppsala

IUCN (International Union for the Conservation of Nature and Natural Resources, World Conservation Union) (2001) IUCN Red List categories and criteria. Version 3.1. IUCN Species Survival Commission, IUCN, Gland and Cambridge

IUCN (2003) Guidelines for application of IUCN Red List criteria at regional levels. Version 3.0. IUCN Species Survival Commission, IUCN, Gland and Cambridge

Jonsell M, Nordlander G (2002) Insects in polypore fungi as indicator species: a comparison between forest sites differing in amounts and continuity of dead wood. For Ecol Manag 157:101-118

Jonsell M, Weslien J, Ehnström B (1998) Substrate requirements of red-listed saproxylic invertebrates in Sweden. Biodivers Conserv 7:749-764

Jonsson M (2003) Colonization ability of the threatened tenebrionid beetle Oplocephala haemorrhoidalis and its common relative Bolitophagus reticulatus. Ecol Entomol 28:159-167

Jonsson M, Jonsell M, Nordlander G (2001) Priorities in conservation biology: a comparison between two polyporeinhabiting beetles. Ecol Bull 49:195-204

> Komonen A (2007) Are we conserving peripheral populations? An analysis of range structure of longhorn beetles in Finland. J Insect Conserv 11:281-285

Komonen A, Penttilä R, Lindgren M, Hanski I (2000) Forest fragmentation truncates a food chain based on an oldgrowth forest bracket fungus. Oikos 90:119-126

Kotiaho JS, Kaitala V, Komonen A, Päivinen J (2005) Predicting the risk of extinction from shared ecological characteristics. Proc Natl Acad Sci USA 102:1963-1967

Martikainen P (2002) Ecology and conservation status of Acanthocinus griseus (Fabricius, 1792) (Coleoptera: Cerambycidae) in Finland. Entomol Fenn 13:41-50

Morris WF, Doak DF (2002) Quantitative conservation biology - theory and practice of population viability analysis. Sinauer Associates, Sunderland, MA

Ranius T (2001) Constancy and asynchrony of Osmoderma eremita populations in tree hollows. Oecologia 126:208-215

Ranius T (2002) Population ecology and conservation of beetles and pseudoscorpions living in hollow oaks in Sweden. Anim Biodivers Conserv 25:53-68

> Ranius T (2007) Extinction risks in metapopulations of a beetle inhabiting hollow trees predicted from time series. Ecography 30:716-726

Ranius T, Kindvall O (2006) Extinction risk of wood-living model species in forest landscapes as related to forest history and conservation strategy. Landscape Ecol 21:687-698

Rassi P, Alanen A, Kanerva T, Mannerkoski I (eds) (2001) The 2000 Red List of Finnish species. Ministry of the Environment and Finnish Environment Institute, Helsinki.

Siitonen J (2001) Forest management, coarse woody debris and saproxylic organisms: Fennoscandian boreal forests as an example. Ecol Bull 49:11-41

> Siitonen J, Saaristo L (2000) Habitat requirements and conservation of Pytho kolwensis, a beetle of old-growth boreal forest. Biol Conserv 94:211-220

Speight MCD (1989) Saproxylic invertebrates and their conservation. Council of Europe, Strasbourg

Tikkamäki T, Komonen A (2006) Population size and structure of the threatened longhorn beetle Leptura maculata. 
In: Book of Abstracts, 1st European Congress of Conservation Biology, Eger, Hungary, 22-26 August 2006

Tikkanen OP, Martikainen P, Hyvärinen E, Junninen K, Kouki

J (2006) Red-listed boreal forest species of Finland: associations with forest structure, tree species, and decaying

Editorial responsibility: Brendan Godley,

University of Exeter, Cornwall Campus, UK wood. Ann Zool Fenn 43:373-383

Wikars LO (2004) Habitat requirements of the pine woodliving beetle Tragosoma depsarium (Coleoptera: Cerambycidae) at $\log$, stand, and landscape scale. Ecol Bull 51:287-294

Submitted: October 12, 2007; Accepted: November 13, 2007 Proofs received from author(s): February 12, 2008 